\title{
Comparative Efficacy of Diode, Nd:YAG and Er:YAG Lasers Accompanied by Fluoride in Dentinal Tubule Obstruction
}

\author{
Shabnam Aghayan $^{1}$, Samaneh Fallah $^{2}{ }^{\circledR}$, Nasim Chiniforush $^{3 *}(\mathbb{0}$ \\ ${ }^{1}$ Department of Periodontology, Faculty of Dentistry, Tehran Medical Sciences, Islamic Azad University, Tehran, Iran \\ ${ }^{2}$ Faculty of Dentistry, Tehran Medical Sciences, Islamic Azad University, Tehran, Iran \\ ${ }^{3}$ Laser Research Center of Dentistry, Dentistry Research Institute, Tehran University of Medical Sciences, Tehran, Iran
}

\author{
*Correspondence to \\ Nasim Chiniforush, \\ DDS, PhD of Laser Dentistry; \\ Address: Dentistry Research \\ Institute, Tehran University of \\ Medical Sciences, Qouds Ave, \\ Tehran, Iran. \\ Postal code: 1441987566 ; \\ Tel: +982183384303; \\ Email: n-chiniforush@sina.tums. \\ ac.ir
}

Received: February 13, 2021 Accepted: June 27, 2021

Published online October 19 2021

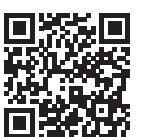

\section{Introduction}

Dentin hypersensitivity $(\mathrm{DH})$ is a common clinical problem affecting all age groups. ${ }^{1}$ It is more commonly seen in canine and premolar teeth of both jaws. ${ }^{2} \mathrm{DH}$ is determined with a short, sharp pain due to the reaction of exposed dentin to different stimuli such as heat, touch, osmotic pressure or chemical stimuli. This pain cannot be attributed to any dental problem or pathology. ${ }^{2}$

Numerous theories have been suggested for explaining the mechanisms of DH. Due to the hydrodynamic theory, which has the highest rate of acceptance, DH occurs when the stimulus causes the movement of intratubular fluid inward or outward and leads to the activation of pain receptors. According to this theory, an ideal treatment for $\mathrm{DH}$ should involve a reduction of intratubular fluid or blocking the pulpal nerve response. ${ }^{3}$

Many desensitizing agents such as potassium nitrate, formaldehyde, composite resins, and varnishes have been suggested to resolve $\mathrm{DH} .{ }^{4}$ Recently, high-level and low-level laser systems were proposed to resolve $\mathrm{DH}$.
However, low-level lasers are more commonly used for this purpose due to their lower cost. ${ }^{5} \mathrm{~A}$ number of studies have evaluated $\mathrm{DH}$ and its efficient management ${ }^{6-8}$ and a few of them have evaluated the efficacy of different laser types for the resolution of $\mathrm{DH}$, reporting contradictory results. ${ }^{6,7}$ Thus, comprehensive information is not available on the efficacy of different laser types for the obstruction of dentinal tubules and the resolution of DH. Lasers can be applied in both low-level power and medium-level power modes by their effect on the nervous level and the occlusion of dentinal tubules respectively. ${ }^{9}$

Considering the significance and relatively high prevalence of $\mathrm{DH}$ and the gap of information regarding the efficacy of different laser types for the resolution of $\mathrm{DH}$, this study aimed to compare the efficacy of $980 \mathrm{~nm}$ diode, Nd:YAG and Er:YAG lasers in the obstruction of dentinal tubules of extracted human teeth.

\section{Materials and Methods}

This experimental study was in vitro. The single-rooted 
human teeth were examined under a stereo microscope, and the teeth with no internal/external root resorption, cracks or root caries were selected. The minimum sample size was considered to be 10 samples in each of the four groups (a total of 40) according to a study by Patil et al, ${ }^{10}$ using one-way ANOVA Power Analysis feature of PASS 11 software assuming alpha $=0.05$, beta $=0.2$, standard deviation of 3.71 and effect size of 0.55 . The study was approved by the ethics committee of Azad university of Medical Sciences.

Twenty sound extracted single-rooted human teeth with no caries or restorations were collected. Soft tissue residues and debris were detached using a dental scaler. The coronal third and apical third of the teeth were cut by a diamond disc and low-speed handpiece under copious irrigation with sterile water. Two sections were made at the mesial and distal tooth surfaces measuring $2 \times 2 \mathrm{~mm}$ with $2 \mathrm{~mm}$ thickness. All samples were then etched with $6 \%$ citric acid and rinsed with distilled water for 1 minute.

The sections were randomly allocated into 4 groups $(n=10)$. Group 1 served as the control group and did not receive any laser irradiation. The samples in group 2 underwent 980nm diode laser (wiser II, Doctor Smile, Italy) irradiation with the flat top handpiece. The samples in group 3 underwent Nd:YAG laser (Lightwalker, Fotona, Slovenia) irradiation with the Genova handpiece, and the samples in group 4 were subjected to Er:YAG laser (Lightwalker, Fotona, Slovenia) irradiation with the bleaching handpiece. Table 1 shows the laser irradiation parameters in the three experimental groups.

The cross-sectional area of all laser hand-pieces was 1 $\mathrm{cm}^{2}$ and the distance from the tip of the laser hand-piece to the surface of the samples was $1 \mathrm{~mm}$. The total irradiation time was 60 seconds, and irradiation was performed in three cycles, 20 seconds each, with 1-minute intervals.

Fluoride varnish (5\% sodium fluoride, TCP and xylitol, Vericom CO LTD., Korea) was applied on the surface of all samples, and the samples in groups 2, 3 and 4 immediately underwent laser irradiation after the application of varnish. After the completion of irradiation, the varnish remained on the surface of the samples for 5 minutes. Excess varnish was then removed and the samples were immersed in artificial saliva. They were then dried using an air dry system, gold-plated and inspected under an electron microscope at $\times 2000$ magnification (Vega/ Tescan - XMU, Tescan s.r.o, Czech Republic) to determine the number of obstructed dentinal tubules and the diameter of open dentinal tubules. The study was performed blindly in such a way that the technician who measured the number and diameter of dentinal tubules was blinded to the group allocation of the samples.

The percentage of open dentinal tubules and their diameter were compared between different groups using one-way ANOVA. Tukey's HSD test was used for pairwise comparisons. The level of significance was considered as $P<0.05$.

\section{Results}

Table 2 shows the mean percentage of obstructed dentinal tubules. The percentage of obstructed dentinal tubules indicated a significant difference between the groups $(P<0.05)$. The results of pairwise comparisons showed that the mean percentage of obstructed dentinal tubules in all three laser groups was significantly higher than that in the control (fluoride varnish) group $(P=0.000)$. The mean percentage of obstructed dentinal tubules in the diode laser group was $4.00000(P=0.236)$ lower than that in the Er:YAG laser group and $2.30000(P=0.688)$ lower than that in the Nd:YAG laser group. The mean difference between the diode laser group and the control group was $49.00000(P=000)$. The difference in the mean percentage of obstructed tubules in the Er:YAG and Nd:YAG groups was $1.70000(P=0.846)$. The difference between the Er:YAG group and the control group in this regard was $53.00000(P=000)$. The difference in the mean percentage of obstructed tubules in the Nd:YAG and control groups was 51.30000. None of the differences were statistically significant $(P>0.05)$.

Table 3 shows the diameter of open dentinal tubules in the groups. As shown, regarding the minimum diameter of open dentinal tubules, the smallest value was noted in the Er:YAG laser group while the largest value was noted in the control (fluoride) group. Regarding the maximum diameter of open dentinal tubules, the highest value was noted in the control group while the smallest value was noted in the Nd:YAG laser group; however, these differences were not statistically significant $(P=0.367)$.

\section{Discussion}

A significant correlation exists between $\mathrm{DH}$ and the presence of open dentinal tubules because exposure of open dentinal tubules to different stimuli would stimulate the pain receptors and lead to $\mathrm{DH} .{ }^{2} \mathrm{DH}$ can be effectively resolved by obstruction of dentinal tubules. ${ }^{11}$ This study assessed and compared the effects of a $980 \mathrm{~nm}$ diode laser, an Nd:YAG laser and an Er:YAG laser on dentinal

Table 1. Laser Irradiation Parameters in the Three Experimental Groups

\begin{tabular}{ll}
\hline Laser Type & Exposure Settings \\
\hline Diode & Flat-top hand-piece, $980 \mathrm{~nm}$ wavelength, continuous mode, $0.5 \mathrm{~W}$ power, $30 \mathrm{~J} / \mathrm{cm}^{2}$ energy density \\
Nd:YAG & Genova hand-piece $1064 \mathrm{~nm}$ wavelength, $0.5 \mathrm{~W}$ power, $10 \mathrm{~Hz}$ frequency, $30 \mathrm{~J} / \mathrm{cm}^{2}$ energy density, $100 \mathrm{~ms}$ pulse duration \\
Er:YAG & Bleaching Hand-piece $2940 \mathrm{~nm}$ wavelength, $0.5 \mathrm{~W}$ power, $10 \mathrm{~Hz}$ frequency, $30 \mathrm{~J} / \mathrm{cm}^{2}$ energy density, $100 \mathrm{~ms}$ pulse duration \\
\hline
\end{tabular}


Table 2. Mean Percentage of Obstructed Dentinal Tubules in the Study Groups $(n=10)$

\begin{tabular}{lcccc}
\hline Group & Minimum & Maximum & Mean & Standard Deviation \\
\hline Diode & 74.00 & 93.00 & 87.2 & 4.96 \\
Er:YAG & 78.00 & 100.00 & 91.2 & 6.28 \\
Fluoride (control) & 33.00 & 45.00 & 38.2 & 4.13 \\
Nd:YAG & 86.00 & 93.00 & 89.5 & 2.27 \\
\hline
\end{tabular}

Table 3. Diameter of open dentinal tubules $(\mu \mathrm{m})$ in the study groups $(n=10)$

\begin{tabular}{lcccc}
\hline Group & Minimum & Maximum & Mean & Standard Deviation \\
\hline Diode & 1.37 & 3.68 & 2.4180 & 0.84 \\
Er:YAG & 0.00 & 3.11 & 1.7980 & 0.98 \\
Fluoride (control) & 1.55 & 5.73 & 2.5120 & 1.36 \\
Nd:YAG & 1.49 & 2.90 & 2.1350 & 0.50 \\
\hline
\end{tabular}

tubule obstruction. The results showed that all three laser types decreased the number of open dentinal tubules in a significant manner, but no significant difference was noted in dentinal tubule obstruction between them $(P>0.05)$. However, the diameter of open tubules in the three laser groups did not show any significant difference from that in the control group.

The Nd:YAG laser is a high-level infra-red laser that easily affects the tooth structure, melts the peritubular dentin and results in its entry into the dentinal tubules and their relative obstruction. As a result, the diameter of open tubules decreases. It confers a dull appearance to dentin. ${ }^{12,13}$

The Er:YAG laser is highly interacted with the structures bonded to water in dentin and thus causes sudden expansion of crystalline tooth structure. It destructs the dentinal tubules in an irregular pattern by the destruction of peritubular dentin. ${ }^{9}$ The $980 \mathrm{~nm}$ diode laser has near infrared wavelength. Thus, part of its energy is absorbed by the mineral content of dentin such as phosphate and carbonate causing disarrangement of the crystalline regular structure of dentin by thermomechanical destruction and melting of dentin. ${ }^{14,15}$

Chiga et $\mathrm{al}^{16}$ assessed the effect of Nd:YAG and Er:YAG lasers with $1 \mathrm{~W}$ power with and without fluoride varnish on the obstruction of dentinal tubules and concluded that both laser types can effectively obstruct the dentinal tubules. The laser wavelengths in our study were similar to those in the study by Chiga et $\mathrm{al}^{16}$; however, the laser power was $0.5 \mathrm{~W}$. Nonetheless, both laser types efficiently obstructed the dentinal tubules. The mechanism of both Nd:YAG and Er:YAG lasers is the same and is through melting and re-solidification of dentin. ${ }^{17-20}$ This can explain the similarity of our results to those of Chiga et al. ${ }^{16}$ They evaluated the effect of the presence and absence of fluoride varnish and found that it had no effect on the obstruction of dentinal tubules. This finding has also been reported by some other studies ${ }^{21,22}$ and justifies the use of fluoride varnish as the control in our study. Kurt et $\mathrm{a}^{23}$ compared the effect of Nd:YAG and Er:YAG lasers and two desensitizing agents, namely NovaMin and PreviDent, on dentinal tubules. They showed that both Nd:YAG and Er:YAG lasers alone effectively decreased the permeability of dentinal tubules. However, statistically, none of the laser groups had any superiority over each other. Similarly, in our study, Nd:YAG and Er:YAG laser irradiation in combination with the application of fluoride varnish showed superior obstruction of dentinal tubules compared to the application of fluoride varnish alone (control group). However, the two laser groups were not significantly different in this respect. Similar results obtained in our study and those in the study by Kurt et $\mathrm{al}^{23}$ may be due to the equal wavelength of lasers and the medium short pulse. However, Kurt et $\mathrm{al}^{23}$ did not assess the effect of the laser in combination with a desensitizing agent.

Saluja et a ${ }^{24}$ assessed the effect of Nd:YAG, $810 \mathrm{~nm}$ diode and $\mathrm{CO}_{2}$ lasers on exposed dentinal tubules of human teeth. They reported that all laser types effectively obstructed the dentinal tubules. However, the Nd:YAG laser was more effective than the other two. The difference between their results and ours may be attributed to higher laser power ( $1 \mathrm{~W}$ in their study compared to $0.5 \mathrm{~W}$ in ours) and distance from the tip of the laser hand-piece to the tooth surface ( $1 \mathrm{~cm}$ versus $2 \mathrm{~mm}$ ) in their study compared to ours. In our study, all three laser types showed equal efficacy. However, it should be noted that the diode laser used in our study had a $980 \mathrm{~nm}$ wavelength, which was different from the wavelength of the diode laser used by Saluja et al. ${ }^{24}$ Öncü et a ${ }^{25}$ evaluated the efficacy of different desensitizing agents and lasers for the obstruction of dentinal tubules. They concluded that the Er:YAG laser combined with Gluma had the highest efficacy for tubular obstruction, which was different from our results. The difference in desensitizing agents used in the two studies may explain the difference in the results. Studies on the efficacy of Gluma and fluoride for resolution of DH have shown that Gluma has a higher desensitizing effect than fluoride ${ }^{22,26}$. Moreover, the higher frequency and power of lasers in the study by Öncü et $\mathrm{al}^{25}$ can explain the difference in the results.

Gholami et $\mathrm{al}^{8}$ compared the effect of Er,Cr:YSGG, Nd:YAG, $\mathrm{CO}_{2}$ and diode lasers on dentinal tubules. They showed that although the mean reduction in diameter of dentinal tubules in the Nd:YAG laser group was higher than that in other groups, the reduction in tubular diameter in all groups was significant. In the current study, no significant difference was noted in the reduction of dentinal tubule diameter between the laser groups. This controversy in the results may be related to the higher power, energy density and frequency of lasers used by Gholami et $\mathrm{al}^{8}$ compared to our study. Nandakumar and 
Iyer $^{27}$ compared the efficacy of Er,Cr:YSGG and diode lasers and some desensitizing agents using an electron microscope. They observed a minimum percentage of open dentinal tubules in the Er,Cr:YSGG laser group with no desensitizing toothpaste, which was different from our result. This controversy can be due to shorter irradiation time and distance of the laser beam from the surface of samples as well as higher diode laser power and frequency of the Er,Cr:YSGG laser in their study compared to ours.

As the flat-top beam profile can create a homogeneous and constant power on the beam spot-area compared to the conventional Gaussian beam profile, it seems that irradiation with a flat-top handpiece can be more effective without producing a remarkable thermal increase. ${ }^{28}$ To our knowledge, this is the first study that evaluates the effect of the flat-top beam profile on dentinal obstruction. Further studies are needed to compare the flat top with the Gaussian beam profile on dentinal obstruction.

As this study was performed in vitro, the generalization of results to the clinical condition should be done with considerations. Further clinical studies are required to confirm the findings of this study.

\section{Conclusion}

$980 \mathrm{~nm}$ diode, Nd:YAG and Er:YAG lasers accompanied by fluoride can effectively obstruct the dentinal tubules.

\section{Conflict of Interests}

The authors declare no conflict of interest.

\section{Ethical Considerations}

This study was in vitro.

\section{Funding}

None.

\section{References}

1. Khoubrouypak Z, Hasani Tabatabaei M, Chiniforush N, Moradi Z. Evaluation of the Effects of $810 \mathrm{~nm}$ Diode Laser Alone and in Combination with Gluma ${ }^{\oplus}$ and Chromophore on Dentinal Tubule Occlusion: A Scanning Electron Microscopic Analysis. J Lasers Med Sci. 2020;11(3):268273. doi: $10.34172 /$ jlms.2020.45.

2. Tabatabaei $\mathrm{MH}$, Chiniforush N, Hashemi G, Valizadeh S. Efficacy Comparison of Nd:YAG laser, diode laser and dentine bonding agent in dentine hypersensitivity reduction: a clinical trial. Laser Ther. 2018; 31;27(4):265270. doi: 10.5978/islsm.27_18-OR-24.

3. West NX, Lussi A, Seong J, Hellwig E. Dentin hypersensitivity: pain mechanisms and aetiology of exposed cervical dentin. Clin Oral Investig. 2013;17 (Suppl 1): S9-19. doi: 10.1007/s00784-012-0887-x.

4. Porto IC, Andrade AK, Montes MA. Diagnosis and treatment of dentinal hypersensitivity. J Oral Sci. 2009; ;51(3):323-32. doi: 10.2334/josnusd.51.323.

5. Sgolastra F, Petrucci A, Gatto R, Monaco A. Effectiveness of laser in dentinal hypersensitivity treatment: a systematic review. J Endod. 2011;37(3):297-303. doi: 10.1016/j. joen.2010.11.034

6. Doshi S, Jain S, Hegde R. Effect of low-level laser therapy in reducing dentinal hypersensitivity and pain following periodontal flap surgery. Photomed Laser Surg. 2014;32(12):700-6. doi: 10.1089/pho.2014.3802.

7. Sanz-Moliner JD, Nart J, Cohen RE, Ciancio SG. The effect of an 810-nm diode laser on postoperative pain and tissue response after modified Widman flap surgery: A pilot study in humans. J Periodontol. 2013;84(2):152-8. doi: 10.1902/jop.2012.110660.

8. Gholami GA, Fekrazad R, Esmaiel-Nejad A, Kalhori KA. An evaluation of the occluding effects of Er; Cr: YSGG, Nd: YAG, CO2 and diode lasers on dentinal tubules: a scanning electron microscope in vitro study. Photomed Laser Surg. 2011;29(2):115-21. doi: 10.1089/pho.2009.2628.

9. Rezazadeh F, Dehghanian P, Jafarpour D. Laser Effects on the Prevention and Treatment of Dentinal Hypersensitivity: A Systematic Review. J Lasers Med Sci. 2019;10(1):1-11. doi: $10.15171 /$ jlms.2019.01.

10. Patil AR, Varma S, Suragimath G, Abbayya K, Zope SA, Kale V. Comparative evaluation of efficacy of iontophoresis with $0.33 \%$ sodium fluoride gel and diode laser alone on occlusion of dentinal tubules. J Clin Diagn Res. 2017;11(8): ZC123-ZC126. doi: 10.7860/JCDR/2017/29428.10526.

11. Dundar A, Yavuz T, Orucoglu H, Daneshmehr L, Yalcin $M$, Sengun A. Evaluation of the permeability of five desensitizing agents using computerized fluid filtration. Niger J Clin Pract. 2015;18(5):601-6. doi: 10.4103/11193077.158949.

12. Glauche CE, de Freitas PM, Vieira Jr ND, Lage Marques JL. Qualitative microanalysis of ions and ultrastructural changes in dentin exposed to laser irradiation and to metal salts solution. Lasers Surg Med. 2005;36(4):334-9. doi: 10.1002/lsm.20153.

13. Kumar NG, Mehta DS. Short-term assessment of the Nd: YAG laser with and without sodium fluoride varnish in the treatment of dentin hypersensitivity-a clinical and scanning electron microscopy study. J Periodontol. 2005;76(7):1140-7. doi: 10.1902/jop.2005.76.7.1140.

14. Santos C, Sousa-Neto MD, Alfredo E, Guerisoli DM, Pecora JD, Comelli Lia RF. Morphologic evaluation of the radicular dentine irradiated with Nd: YAG laser under different parameters and angles of incidence. Photomed Laser Surg. 2005;23(6):590-5. doi: 10.1089/pho.2005.23.590.

15. Umana $M$, Heysselaer D, Tielemans $M$, Compere $P$, Zeinoun T, Nammour S. Dentinal tubules sealing by means of diode lasers (810 and $980 \mathrm{~nm}$ ): a preliminary in vitro study. Photomed Laser Surg. 2013;31(7):307-14. doi: 10.1089/pho.2012.3443.

16. Chiga S, Toro CV, Lepri TP, Turssi CP, Colucci V, Corona SA. Combined effect of fluoride varnish to Er: YAG or Nd: YAG laser on permeability of eroded root dentine. Arch Oral Biol. 2016; 64:24-7. doi: 10.1016/j.archoralbio.2015.12.006.

17. Zapletalová Z, Peřina Jr J, Novotný R, Chmelíčková H. Suitable conditions for sealing of open dentinal tubules using a pulsed Nd: YAG laser. Photomed Laser Surg. 2007;25(6):495-9. doi: 10.1089/pho.2007.2085.

18. Corrêa Aranha AC, Domingues FB, Franco VO, Gutknecht N, De Paula Eduardo C. Effects of Er: YAG and Nd: YAG lasers on dentin permeability in root surfaces: a preliminary 
in vitro study. Photomed Laser Surg. 2005;23(5):504-8. doi: 10.1089/pho.2005.23.504.

19. Al-Saud LM, Al-Nahedh HN. Occluding effect of Nd: YAG laser and different dentin desensitizing agents on human dentinal tubules in vitro: a scanning electron microscopy investigation. Oper Dent. 2012;37(4):340-55. doi: 10.2341/10-188-L.

20. Badran Z, Boutigny H, Struillou X, Baroth S, Laboux O, Soueidan A. Tooth desensitization with an Er: YAG laser: in vitro microscopical observation and a case report. Lasers Med Sci. 2011;26(1):139-42. doi: 10.1007/s10103-0100835-4.

21. Idon PI, Esan TA, Bamise CT. Efficacy of Three In-Office Dentin Hypersensitivity Treatments. Oral Health Prev Dent. 2017;15(3):207-214. doi: 10.3290/j.ohpd.a38523.

22. Sivaramakrishnan G, Sridharan K. Fluoride varnish versus glutaraldehyde for hypersensitive teeth: a randomized controlled trial, meta-analysis and trial sequential analysis. Clin Oral Investig. 2019;23(1):209-220. doi: 10.1007/ s00784-018-2428-8.

23. Kurt S, Kırtıloğlu T, Yılmaz NA, Ertaş E, Oruçoğlu H. Evaluation of the effects of Er: YAG laser, Nd: YAG laser, and two different desensitizers on dentin permeability: in vitro study. Lasers Med Sci. 2018 ;33(9):1883-1890. doi: 10.1007/s10103-018-2546-1.

24. Saluja M, Grover HS, Choudhary P. Comparative morphologic evaluation and occluding effectiveness of $\mathrm{Nd}$ : YAG, CO2 and diode lasers on exposed human dentinal tubules: an invitro SEM study. J Clin Diagn Res. 2016;10(7): ZC66-70. doi: 10.7860/JCDR/2016/18262.8188.

25. Öncü E, Karabekiroğlu S, Ünlü N. Effects of different desensitizers and lasers on dentine tubules: An in-vitro analysis. Microsc Res Tech. 2017;80(7):737-744. doi: 10.1002/jemt.22859.

26. Abuzinadah $\mathrm{SH}$, Alhaddad AJ. A randomized clinical trial of dentin hypersensitivity reduction over one month after a single topical application of comparable materials. Sci Rep. 2021;11(1):6793. doi: 10.1038/s41598-021-86258-3.

27. 27.Nandakumar $\mathrm{A}$, Iyer $\mathrm{VH}$. In vitro analysis comparing efficacy of lasers and desensitizing agents on dentin tubule occlusion: a scanning electron microscope study. Int $J$ Laser Dent. 2014;4(1):1-7. doi: 10.5005/jp-journals-10022-1048

28. Abdel Hamid MA, Zaied AA, Zayet MK, Abdelmageed H, Hassan EA, Amaroli A. Efficacy of Flat-Top Hand-Piece Using $980 \mathrm{~nm}$ Diode Laser Photobiomodulation on Socket Healing after Extraction: Split-Mouth Experimental Model in Dogs. Photochem Photobiol. 2021;97(3):627-633. doi: 10.1111/php.13356. 